\title{
Article
}

\section{Enterprise work safety standardization optimization mode on VSM in China}

\author{
Dunwen Liu, Chun Gong *, Yinghua Jian \\ School of Resources and Safety Engineering, Central South University, Changsha, 410083, China; \\ dunwen@csu.edu.cn (L.D.); jyh_0412@csu.edu.cn (J.Y.) \\ * Correspondence: gongchun@csu.edu.cn
}

\begin{abstract}
The work safety standardization of enterprises based on the traditional work safety theory has played a significant role in reducing the number of accidents and improving work safety to some extent in China. However, some problems are coming with the work safety standardization of enterprises developing constantly in China. On the one hand, it is not combined with the actual situation of the enterprise, lacking pertinence and specificity, these defects resulted that it is not integrated with original safety production management system of enterprise and make it difficult to carry out. On the other hand, there is a lack of systematic management methods for the work safety management system of enterprise, most of enterprises only pay attention to the inspection result rather than the process control. This means after the check of the government, many enterprises will relax to carry out the system. This paper puts forward a new method for optimizing the standardization management mode of work safety based on the Viable System Model (VSM), which can solve the defects of work safety standardization of enterprises management system. An optimization model of work safety standardization based on VSM was construct for explaining the process optimization and control of work safety standardization management. It can improve the connectivity between the enterprise and the government. The conclusion of this paper can provide reference for achieving the development and optimization of work safety standardization of enterprises in China.
\end{abstract}

Keywords: Work safety standardization;Viable System Model;Chinese enterprise;Safety process control.

\section{Introduction}

At the beginning of new China in1949, there is almost no modern industry. After several years of economic recovery, China has launched a series of five-year plans to open a new era of economic development:from the backward agricultural producing countries to the advanced industrial producing countries, and then an independent and complete industrial system has been established. With the development of industrial production, the economy has developed rapidly, but rapid economic speed has certain negative effect on work safety[1]. Large-scale industrialization combined with the lack of systematic safety management has led to more and more safety production accidents, which poses a huge threat to people's lives and property. There have been many documents on safety standards in the world. The United States is one of the countries that attaches the most importance to standardization in the world. In the 1970s, the United States built a relatively complete standard system for the general industrial industry, involving a wide range of issues related to occupational safety and health[2].With the danger of safety production accidents, China began to learn from the foreign safety standardization system, and formed the normative documents of the "Basic Standards for Enterprise Safety Production Standardization" in the gradual development. According to literature statistics, in recent years, with the support and encouragement of Chinese governments at all levels, the work safety situation has been improve. in China[3-5], However, work safety accidents still occur frequently, occupational diseases have not been 
effectively prevented and controlled, and there are many limitations in work safety management $[4,6]$.

In 1964, the concept of coal mine quality standardization was first put forward in China[7];After decades of development, the full text of the new version of the "Production Safety Law of the People's Republic of China" was revised in 2015, and new regulations for the construction of work safety standards were added. The production and operation units were required to carry out work safety standardization with the content of the qualified position standards, professional standards and corporate standards, and strengthen the basic work of safety production. Link the work safety standardization level to the work injury insurance rate. At the same time, it is stipulated that the relevant regulatory authorities need to conduct a graded assessment of the work safety standardization construction of the production and operation units, and the information is disclosed, and the rating results will be used as an important reference for the credit rating of the production and operation units[8].Enterprise work safety standardization has a positive effect on safety production, but its evaluation and implementation process is not systematic. The whole promotion work relies too much on top-down assessment. It is the government's regional compliance target, but the specific compliance must be completed by the enterprise. Inevitably, the phenomenon of "two skins" is formed. The "two skins" means two things that have a necessary connection or dependency relationship are separated. In this case, it means that the work safety standardization system is completely separated from the daily safety management. Therefore, it is very important to establish a systematic enterprise work safety standardization system, which can guide daily safety management. In China, the traditional "work safety standardization system" adopts the "PDCA" cycle principle. The government departments rate the products according to the results of the implementation of work safety standardization, and lack of process control, resulting that the company only paid attention to the result and neglected the process safety. In the work safety standardization now, some units have the problem of "pay attention to establishment and disregard implementation". After the standard is released, the propaganda and implementation work cannot be deployed in time, and there is no supervision and inspection of the standard implementation, which result in failure to promptly guide safety production after the release of some standards, even being shelved, became a face project[9].These enterprises are solely for the purpose of fulfilling the tasks assigned by the government departments. After coping with the inspections of relevant departments, they will relax the implementation of work safety standardization, thus leading to high safety risk.

To this end, based on the analysis of the traditional work safety standardization system, this paper attempts to join the process management and control, and introduces the idea of cybernetics in management science into the work safety standardization system. This paper will refer to the Beer's Viable System Model(VSM). Prior to this, VSM has been used in various fields, for examples, Gary Preece[10] used VSM for case studies of disaster response, it explicitly models communication channels providing detailed relationships between elements in organisations; and it breaks away from looking at organisations in terms of their hierarchical management structures which are ineffective when sharing information during disaster response.Panagiotis D. Panagiotakopoulos[11] used VSM to solve the significant gap between their adoption and the implementation of sustainability into every level of the organisation.Angela Espinosa [12] used the Viable System Model as a hermeneutical enabler of the community learning process concerning their self-organisation: by embedding VSM distinctions, they redesigned their primary tasks and developed meta-systemic management tools to deal with the complexity they were facing.By using VSM to optimize the enterprise work safety standardization system, which can be promoted more effectively, and improved the connectivity between the enterprise and the government,and in general, their viability and sustain-ability.Gary Preece [13]shows how applying VSM identified generic gaps and opportunities for communication systems and shows how these case studies signal the utility of VSM structures to arranging communications for fast-paced and changing environments. Through literature research, we found that VSM is used for problem-solving in the areas of IT, Policy Making, Production, Social Issues, Organizational Architecture , Knowledge 
Management , Software Development, Business Process, Project Management, Safety, Services, SMEs, Disaster Management, Risk Management, Supply Chain Management etc[14]. And VSM can well realize the division of labor and interconnection between various elements of the system and information feedback functions, which are suitable for the improvement of the enterprises work safety standardization in China.

\section{Materials and Methods}

Adopting the traditional work safety standardization of enterprise system for safety production guidance can reduce the occurrence of accidents to a certain extent. However, from the perspective of a large number of safety production accidents occurring in China every year, the traditional work safety standardization of enterprise system has some defects, it lacks process control for dangerous and harmful factors in the production process.

The traditional work safety standardization of enterprise system only focuses on the safety of results regardless of the production process. For example, the safety standardization rating of a company is based on the company's self-assessment report, some writing materials about daily safety management and on-site external review, and they can write this material in their own way, whether or not these safety activities are implemented. So it is hard to know whether the enterprise conducts regular emergency drills, regular safety checking, and regular safety education etc.

To solve the defects of the traditional work safety standardization of enterprise system, this paper introduces the idea of cybernetics in management science. "management cybernetics" is a combination of system control and management sciences, which was put forward by Beer, a theorist in the field of systems theory[10,15,16].Integrating cybernetics into safety management can strengthen the process management and control, improve the viability of the entire system, and ensure the safety of company throughout the production process.

\section{Theory}

The situation of safety production accidents in Chinese enterprises is severe. If the cybernetics in management science was introduced into the work safety standardization system of Chinese enterprises, so that every process of enterprise production can be controlled, the frequency of enterprise safety production accidents will be greatly reduced.

This paper will introduce VSM of management cybernetics, the VSM which was proposed by Beer in his book entitled "Heart of Enterprise"[17], specifies that five functions are needed in a system to ensure its'viability'[10].VSM theory is subordinate to management science. It is a method of using cybernetics to study organizational operations and it mainly studies how organizations maintain stable development in an environment of high diversity and complexity.The basic principles of the Viable System Model are: recursion, autonomy, cohesion and viability[10,15,16]. This structure enables the system to recognize internal disturbances and changes in its environment and to react appropriately[18,19].A simplified model of the VSM with Espejo and Gill's naming conventions shown in Fig. 1. 


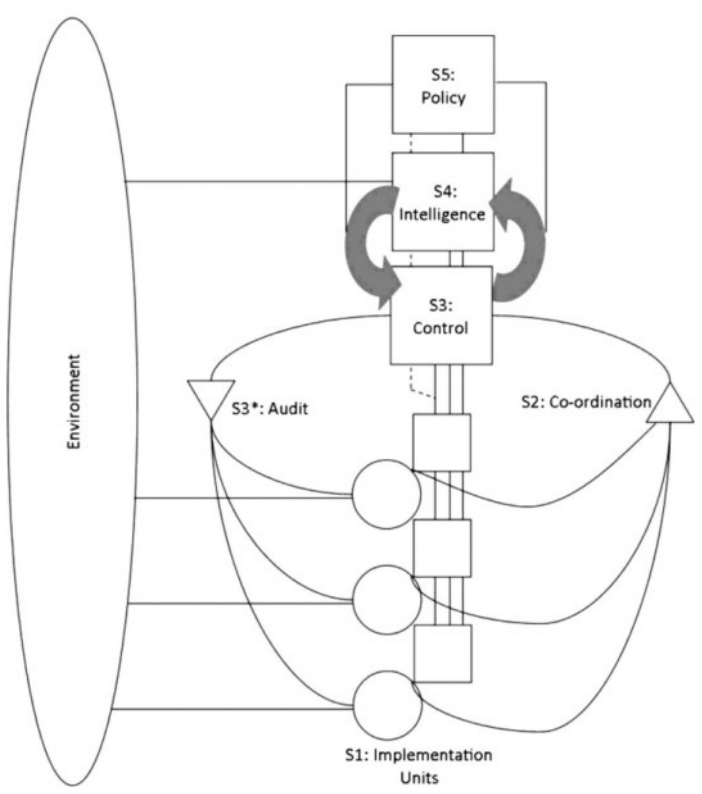

Figure1.Simplified version of Beer's VSM[20] with Espejo and Gill's [21]S1-S5 naming conventions.

Lines in Fig. 1 depict communication channels between systems, One channel (the dotted line in Fig. 1) connecting S5 to S1 carries what is called the algedonic signal, and this signal allows S1 to bypass S2-S4 and directly alert S5 to potential danger, enabling more rapid responses[10].From Espejo and Gill [21], the five functions making up the VSM structure are in table 1.

Table 1.5 system in VSM

\begin{tabular}{|c|c|c|}
\hline System & Name & Function \\
\hline S1 & $\begin{array}{l}\text { Implementatio } \\
\mathrm{n}\end{array}$ & performs the tasks to accomplish system goals \\
\hline S2 & Co-ordination & ensures synergy to perform implementations \\
\hline S3 & Control & $\begin{array}{l}\text { monitors implementations and operations to maintain } \\
\text { efficiency and allocate resources as well as audit } \\
\text { performance }\end{array}$ \\
\hline $\mathrm{S}^{*}$ & Audit & $\begin{array}{l}\text { Authenticity check of internal information uploaded by S2 } \\
\text { and S3 }\end{array}$ \\
\hline S4 & Intelligence & $\begin{array}{c}\text { develops strategic options for the system to adapt to its } \\
\text { environment }\end{array}$ \\
\hline S5 & Policy & sets the overall direction of the system \\
\hline
\end{tabular}

A feature of VSM is recursion, which stipulates each viable system is "embedded in other more comprehensive systems"[22]. The systems are nested inside each other. Each small system is subordinate to a large system, and this large system is subordinate to a larger system. And each system can be operated independently, which makes the part of the whole system clear, and each system interacts with each other, making management more efficient.

\section{Results and Discussion}

\subsection{Enterprise work safety standardization optimization mode on VSM}

This paper applied the idea of cybernetics in management science, and the VSM model to the construction and implementation of work safety of enterprise standardization,which added the process management and control, considered the factors of the external environment, and can more effectively improve the safety production level of enterprises.

The work safety standardization of enterprise system is under the overall production safety goal set by the enterprise, and the interaction of each subsystem is coordinated to achieve the safety 
production goal. Based on the VSM optimization model, the Chinese work safety standardization of enterprise system has become a "viable system" consisting of five large systems. Each system has its functional position, and each system interacts with each other to ensure the effective implementation of work safety of enterprise standardization. Its optimization model is shown in Figure 2.

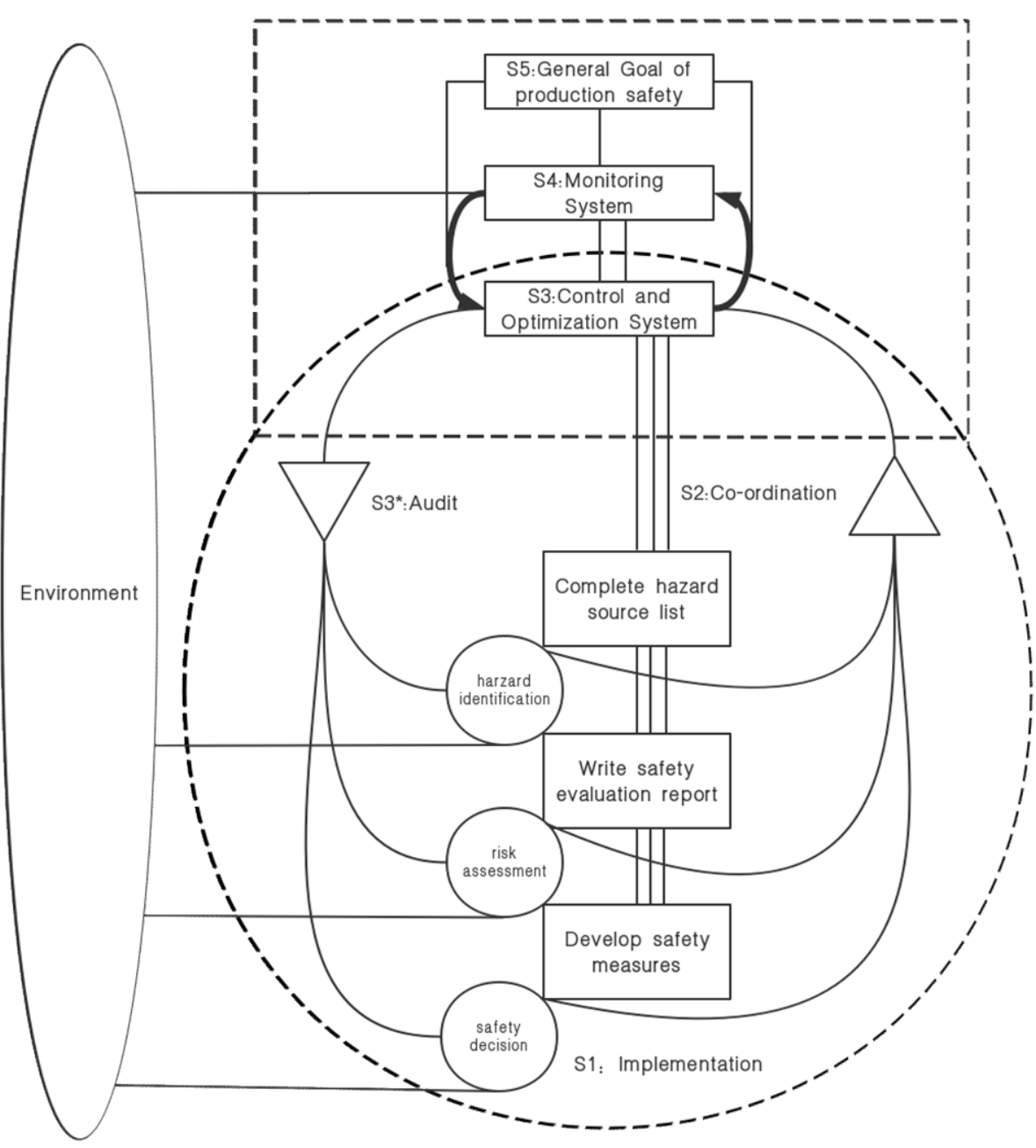

Figure2.The optimization model of Chinese work safety standardization of enterprise based on the VSM

$\mathrm{S} 1$ is the implementation system, and the S1 system is connected to the external environment. They can be contacted and coordinated in various ways. The S1 system consists of three implementation steps, including improving the list of hazard sources, writing safety evaluation reports, and developing corporate safety measures. First, companies identify hazard sources based on their external environment and improve the list of hazard sources for the company, rather than drawing on the list of hazard sources from other companies as a source of risk for the company. Then, according to the list of hazard sources of the company, appropriate risk assessment methods are adopted for risk factors and weak links to estimate the risk factors and the risk level of the weak links, and write a safety evaluation report to record. Safety assessment not only considers the dangerous substances and dangerous structures in the system, but also considers the system's safety and security system and its interaction with hazardous materials and dangerous structures, which requires analysis of the external environmental factors. Finally, according to the results of the safety assessment, for the risk factors beyond the safety indicators, it is necessary to analyze the causes and develop corresponding safety measures, and make safety decisions. 
$\mathrm{S} 2$ is a coordination system. It is to verify whether the S1 system is implementing in place according to some laws, regulations, various standards and regulations, and to coordinate and improve the leakage caused by the implementation process. The effectiveness of the S1 system can be reviewed by establishing an internal review team (enterprise self-assessment) and by hiring external review experts (external review) to align with external environment of company.

S3 is a control and optimization system, which can achieve optimization of the overall goal,and provide coordination and distribution of safety inputs to avoid waste or insufficient investment in safety inputs. In order to realize the functions of the S1 system, there must be sufficient safety investment and some other resources. The S3 system plays a role of "coordinating management", and effectively control the input of each implementation measure and optimizing the distribution system to improve the effective utilization of resources invested by the system, which indirectly improving the return on investment of enterprises, namely safety production is the benefit.

The S3* system is a audit system. It is an auxiliary system of the S3 system. Its function is to review and ensure that all the optimized control scheme specified by the S3 system is implemented in the S1 system. The S3* system acts as a feedback message to ensure information integrity between the S1 system and the S3 system.

The S4 system is a monitoring system. Compared with the control function of the S3 system, S3 only controls and optimizes the implementation process of the entire work safety standardization.The S4 system must take into account the the entire external environment and implementation of work safety of enterprise standardization, and monitors each process and the external environment,and passes the non-conformance information to the S3 system to improve the non-conformance through the control optimization function of the S3 system, and achieves continuous improvement of safety production. At the same time, the S3 system also feeds back the enterprise safety production status to the S4 system to realize the information exchange between the S3 and S4 systems, which can ensure the effective implementation of the work safety standardization system.

The S5 system is a policy system that combines the external environment of the enterprise to set the overall goal of enterprise production safety. The S5 system grasps the direction of implementation of enterprise work safety standardization, adjusts the relationship between S3 system and S4 system, makes adjustments to policies according to the information feedback from S3 system and S4 system in time, and adjusts according to changes in external environment, which can made the enterprise production safety level spirally rising.

The black dotted circle in Figure 2 contains the S1, S2, and S3 (S3*) systems. The combination of these three systems can constitute a small "viable system" that is responsible for the implementation of daily work safety standardization. This small system can complete the work without the interference of the external environment. When the external environment changes, the S4 and S5 systems need to adjust to ensure the overall direction of the implementation of the work safety standardization system.

\subsection{Comprehensive rating of risk matrix for the model}

The risk matrix is an effective risk management tool, which can be used to analyze the potential risks of the project as well as the potential risks of a certain method[23].The risk matrix is a two-dimensional matrix diagram.The horizontal and vertical coordinates of the risk matrix represent different meanings.The horizontal coordinate represents the severity of the risk and the vertical coordinate represents the frequency of risk occurrence, which is usually called risk probability[24].We modify the horizontal and vertical coordinates of the risk matrix to match the work safety standardization of this article.The horizontal coordinate represents the validity of implementing safety standardization, i.e. the quality of the process. The vertical coordinate represents the integrality of the implementation of safety standardization, which means the quantity of relevant laws and regulations that the system can match.According to the validity and integrality classification in Table 2 and Table 3 , the comprehensive rating result can be obtained by calculating the relationship between validity $(\mathrm{V})$ and integrality(I). The comprehensive rating result matrix is shown in Figure 3. 
Table 2. Validity classification

\begin{tabular}{|c|c|c|}
\hline Validity(V) & Level & Definition \\
\hline Excellent & V1 & $\begin{array}{c}\text { The system can effectively promote the safety production of the } \\
\text { enterprise, and poses no safety threats to the entire environment, } \\
\text { equipment and personnel. }\end{array}$ \\
\hline Good & $\mathrm{V} 2$ & $\begin{array}{l}\text { The equipment safety may be slightly neglected during the } \\
\text { implementation process of the system, but it it has no impact on } \\
\text { personnel and the environment. }\end{array}$ \\
\hline Moderate & V3 & $\begin{array}{c}\text { Several serious equipment damage issues are not taken into } \\
\text { consideration, but there was no impact on personnel and the } \\
\text { environment. }\end{array}$ \\
\hline Bad & V4 & $\begin{array}{l}\text { Some serious equipment problems and minor environmental } \\
\text { problems not taking into consideration, resulting in undesirable } \\
\text { consequences and slight threat to personnel safety. }\end{array}$ \\
\hline Ivalid & V5 & $\begin{array}{c}\text { Serious equipment problems and environmental problems are } \\
\text { ignored, resulting in significant consequences and possibly severe } \\
\text { threats to personnel safety. }\end{array}$ \\
\hline
\end{tabular}

Table 3. Integrality classification

\begin{tabular}{|c|c|c|}
\hline $\begin{array}{c}\text { Integrality（I } \\
\text { ) }\end{array}$ & Level & Definition \\
\hline Conform & I1 & $\begin{array}{l}\text { All parts of the system are implemented in strict accordance with the } \\
\text { relevant laws and regulations }\end{array}$ \\
\hline $\begin{array}{l}\text { Relatively } \\
\text { conform }\end{array}$ & I2 & $\begin{array}{l}\text { The implementation of each part of the system basically meets the } \\
\text { requirements of laws and regulations, and a small number of laws } \\
\text { and regulations are not mentioned. }\end{array}$ \\
\hline $\begin{array}{l}\text { Generally } \\
\text { conform }\end{array}$ & I3 & $\begin{array}{l}\text { A small number of parts of the system do not meet the requirements } \\
\text { of laws and regulations, and a small number of laws and regulations } \\
\text { are not mentioned. }\end{array}$ \\
\hline Not conform & $\mathrm{I} 4$ & $\begin{array}{l}\text { More than half of the parts of the system do not meet the } \\
\text { requirements of laws and regulations, and there are many laws and } \\
\text { regulations that have not been mentioned. }\end{array}$ \\
\hline
\end{tabular}

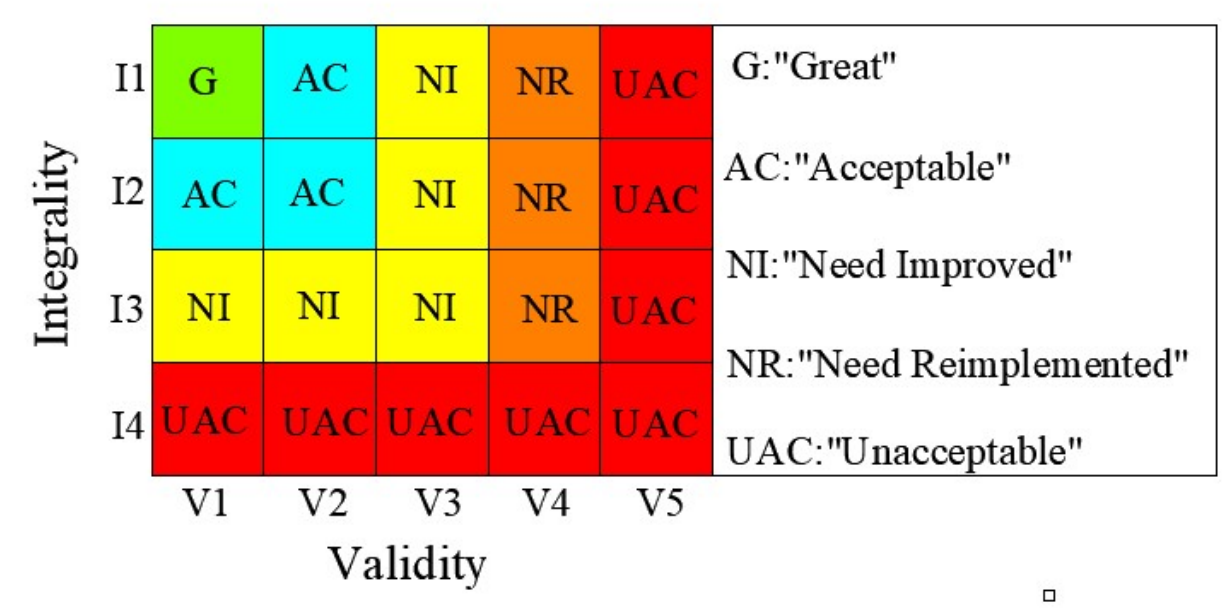

Figure3.Comprehensive rating result matrix 
In the work safety standardization system, we evaluate the validity and integrity of each part of the system, and divide the safety standardization system into three evaluation levels as shown in Table 4. By determining the comprehensive rating of the improved safety standardization system to evaluate the completion of the safety standardization system, and to regulate the implementation of enterprise safety standardization, the system will help restrain the unsafe behavior of the enterprise and improve safety.

Table 4. Comprehensive classification

\begin{tabular}{|c|c|c|}
\hline Level & Definition & Condition \\
\hline I & Meet the requirements & $\begin{array}{l}\text { The comprehensive evaluation results of } \\
\text { the system must be " } \mathrm{G} \text { " or " } \mathrm{AC} \text { " }\end{array}$ \\
\hline II & Acceptable after rectification & $\begin{array}{l}\text { The comprehensive evaluation results } \\
\text { contains "NI" or "NR" but without "UAC" } \\
\text { and the proportion of "NR" does not exceed } \\
50 \% \text {. }\end{array}$ \\
\hline III & $\begin{array}{l}\text { Does not meet the standards, } \\
\text { closed for rectification }\end{array}$ & $\begin{array}{c}\text { The comprehensive evaluation results } \\
\text { contains "UAC" or more than } 50 \% \\
\text { (including } 50 \% \text { ) of the evaluation results are } \\
\text { "NR". }\end{array}$ \\
\hline
\end{tabular}

\subsection{The advantage of the model}

The work safety standardization of enterprise optimization model based on the VSM is a product of safety theory innovation, and provides a methodology to improve and implement work safety of enterprise standardization in China better. Work safety of enterprise standardization in China is in the stage of rapid development. For the current development situation, there are still many problems in the implementation of work safety standardization, such as "pay attention to establishment and disregard implementation", "heavy results, light process", "being perfunctory" and so on. Above mentioned problems deeply reflect the lack and neglect in many aspects of the traditional implementation of work safety standardization. Therefore, it is extremely necessary to optimize the traditional implementation process of work safety standardization, strengthen process management and control, and promote enterprise safety production.Specifically, the work safety of enterprise standardization optimization model based on the VSM has the following advantages compared with the traditional model.

The work safety of enterprise standardization optimization model based on the VSM has a feedback system, which makes the work safety of enterprise standardization system more comprehensive and more efficient through layer-by-layer feedback and information exchange. Firstly, through the feedback and information exchange of all levels of systems, the external environment and various variables are taken into account, making the work safety standardization system be more in line with the company's own situation. Secondly, the new feedback system greatly improves the efficiency of system information transmission, and helps the entire system to improve and update relevant information in a timely manner, thereby improving the efficiency of the system.

Compared with the traditional work safety standardization of enterprise standardization model, this optimization model makes the work safety standardization system more integrated and coordinated. The traditional model is a cyclical process based on the principle of "PDCA". There is less interaction between the each link. In the new model, the interaction between the each link are very close, they influence and feed back each other. So that the resource information of the entire system construction is shared and coordinated in time.

The risk matrix is used to comprehensively rate the implementation of the enterprise's safety standardization system, and evaluate the validity and integrality of the system implementation, by the two dimensions of quality and quantity, the evaluation results are more comprehensive and accurate.

Work safety standardization of enterprise standardization in China is in the process of rapid development.The people are thinking about how to effectively solve the problems arising in work safety standardization of enterprise in China. Enterprise work safety standardization optimization 
mode on VSM proposed in this paper can provide some ideas for the work safety standardization construction of Chinese enterprises, and put the idea of cybernetics in management science into safety management, which provides a feasible way for the development of work safety standardization of enterprise in China.

\section{Conclusions}

The use of VSM to optimize the design of work safety standardization of enterprise provides a new methodology for enterprises to implement work safety standardization management, so that enterprises can develop a standardization system, which adapts to the company's own conditions according to the external environment. The VSM was applied in the work safety standardization to improve the standardization of safety production in Chinese enterprises and to promote the safe production. Enterprise work safety standardization optimization mode on VSM included five functions: implementation function, coordination function, control and optimization function, monitoring function, and policy function. It also conducts a comprehensive matrix rating from the implementation validity and the integrality of compliance with laws and regulations to comprehensively and accurately evaluate the safety standardization system level.Compared with the traditional work safety standardization implementation process, it has monitoring and coordination functions, which can timely monitor the problems generated in the implementation process, and solve the problems of "pay attention to establishment and disregard implementation" of the current enterprise, and timely guide the production behavior.

Putting management science into the idea of safety management complemented the content of safety science and provided ideas for safety issues such as safety management in China. In short, with the development of technology and information, more and more other sciences will be applied to safety science to enrich the content of safety science. The enterprise work safety standardization optimization model on VSM will be more widely used.

\section{Recommendation for future research}

This paper only discussed the work safety of enterprise standardization optimization model, and the practical application of work safety standardization should be further refined and discussed.

Author Contributions: D.L. and G.C. conceived and designed the paper;G.C and Y.J. wrote the paper. All authors have read and agreed to the published version of the manuscript.

Conflicts of Interest: The authors declare no conflict of interest.

\section{References}

1. He, X.; Song, L. Basic Characteristics of Work Safety in China. Procedia Engineering 2011, 26, 1-9.

2. Hongjie, $\mathrm{S}$. Consideration on constructing safety standard system in China . Journal of Safety Science and Technology 2008, 92-96.

3. Wei, J.; Zhou, L.; Wang, F.; Wu, D. Work safety evaluation in Mainland China using grey theory. Appl Math Model 2015, 39, 924-933.

4. Wang, B.; Wu, C.; Kang, L.; Reniers, G.; Huang, L. Work safety in China's Thirteenth Five-Year plan period (2016-2020): Current status, new challenges and future tasks. Safety Sci 2018, 104, 164-178.

5. Wang, B.; Wu, C.; Huang, L.; Kang, L.; Lei, Y. Safety science as a new discipline in China. Safety Sci 2020, 121, 201-214.

6. Zhong, M.; Liu, T.; Deng, Y.; Shi, C.; Fu, T.; Hu, X. Safety evaluation: Important safeguard of work safety for enterprises in China. J Loss Prevent Proc 2006, 19, 762-768.

7. Cannan, Y.; Hong, H.; Chao, W.; Kebing, L.; Aliahmad, A. Comparative study on work safety standardization and DuPont safety management system. China Safety Science Journal 2014, 24, 110-116. 
10 of 10

8. State Administration Of Work Safety (SAWS) Production Safety Law of the People's Republic of China. In 2015.

9. Jiangli, W. Study on necessity and framework of railway work safety standard system. China Safety Science Journal 2018, 28, 131-134.

10. Preece, G.; Shaw, D.; Hayashi, H. Using the Viable System Model (VSM) to structure information processing complexity in disaster response. Eur J Oper Res 2013, 224, 209-218.

11. Panagiotakopoulos, P.D.; Espinosa, A.; Walker, J. Sustainability management: insights from the Viable System Model. J Clean Prod 2016, 113, 792-806.

12. Espinosa, A.; Walker, J. Complexity management in practice: A Viable System Model intervention in an Irish eco-community. Eur J Oper Res 2013, 225, 118-129.

13. Preece, G.; Shaw, D.; Hayashi, H. Application of the Viable System Model to analyse communications structures: A case study of disaster response in Japan. Eur J Oper Res 2015, 243, 312-322.

14. Vahidi, A.; Aliahmad, A.; Teimouri, E. Evolution of Management Cybernetics and Viable System Model. Syst Pract Act Res 2019, 32, 297-314.

15. Brecher, C.; Müller, S.; Breitbach, T.; Lohse, W. Viable System Model for Manufacturing Execution Systems. Procedia CIRP 2013, 7, 461-466.

16. Rahayu, S.; Zulhamdani, M. Understanding Local Innovation System as an Intelligent Organism Using the Viable System Model Case Study of Palm Oil Industry in North Sumatra Province. Procedia - Social and Behavioral Sciences 2014, 115, 68-78.

17. Beer, S. The heart of enterprise. Chichester:John \& Sons.: 1979; p 136.

18. Espinosa, A.; Reficco, E.; Martínez, A.; Guzmán, D. A methodology for supporting strategy implementation based on the VSM: A case study in a Latin-American multi-national. Eur J Oper Res 2015, 240, 202-212.

19. Espinosa, A.; Harnden, R.; Walker, J. A complexity approach to sustainability - Stafford Beer revisited. Eur J Oper Res 2008, 187, 636-651.

20. Beer, S. Diagnosing the system for organisations. Chichester:John \& Sons.: 1985; p 136.

21. Espejo, R.; Gill, A. The Viable System Model as a Framework for Understanding Organizations. Phrontis Ltd. \& SYNCHO Ltd.: 1997; p.

22. Leonard, A. The viable system model and knowledge management. Kybernetes 2000, 29 (5/6), 710-715.

23. Marhavilas, P.K.; Filippidis, M.; Koulinas, G.K.; Koulouriotis, D.E. The integration of HAZOP study with risk-matrix and the analytical-hierarchy process for identifying critical control-points and prioritizing risks in industry - A case study. J Loss Prevent Proc 2019, 62, 103981.

24. Wang, R.; Wang, J. Risk Analysis of Out-drum Mixing Cement Solidification by HAZOP and Risk Matrix. Ann Nucl Energy 2020, 147, 107679. 